\title{
Thoughts on the Mode of Training Graduate Students of Part-time Professional Degrees
}

\author{
Qing-Xiu PENG, Li DING \\ School of Economics and Management, Zhengzhou University of Light Industry, Zhengzhou, \\ China \\ School of Economics and Management, Zhengzhou University of Light Industry, Zhengzhou, \\ China \\ pengqingxiu@163.com,594822001@qq.com
}

Keywords: part-time postgraduate, education Training mode, Education reform, Problems and countermeasures

\begin{abstract}
Coordinating the development of full-time and part-time postgraduate education, standardizing the management of part-time postgraduate education. In September 2016, the General Office of the Ministry of Education issued the "Notice on Coordinating Full-time and Part-time Postgraduate Management" (Teaching and Research) Hall [2016] No. 2) clearly defines the concept of full-time postgraduate and part-time postgraduate students. It mainly separates the two from the form of study. Full-time graduate students are all off-campus in school, and part-time graduate students adopt various methods. And flexible scheduling for non-off-the-job learning.
\end{abstract}

\section{Introduction}

According to the new policy, part-time postgraduate and full-time graduate students adhere to the same standard, guaranteeing the enrollment policy and training standards of the unified examination, and their academic degree certificates have the same legal status and the same effect. Part-time postgraduate education will be included in the qualification assessment of degree authorization points, and the dissertation of part-time postgraduate students will also be included in the sampling. Therefore, the introduction of the new policy puts forward higher requirements for part-time postgraduate education, which is of great significance for standardizing part-time postgraduate education, promoting school running, optimizing structural adjustment, and promoting the improvement of overall teaching quality. Improving the overall quality of postgraduate education is conducive to the promotion of a learning society.

\section{Characteristics of part-time graduate students under the new enrollment system}

\section{In the quality of the source}

The enrollment of part-time postgraduate students should be compared with the national postgraduate entrance examination for entrance examinations. The difficulty of examination and the difficulty of admission are obviously increased, and the threshold for admission is significantly improved. The basic knowledge of candidates who can be admitted is relatively Solid, able to master the solid basic theory and system expertise of the discipline. With the 
examination policies and standards that are consistent with full-time graduate students, the part-time examinations that take the exam must meet the requirements of the initial test, so the quality of the students is significantly improved.

\section{On the source of students}

The students of the in-service postgraduate students come from the part of the incumbent, which is called the source of social personnel. The implementation of the new enrollment system, the incumbent status is no longer a necessary condition for the application, and the undergraduate graduates become an important source of postgraduate degree students. This year is the second year of the implementation of the new regulations of the Department of Education. A considerable number of candidates who originally applied for full-time examinations were not listed on the list for various reasons, but they were admitted to the postgraduate program by the school. With the progress of the policy, there will be a considerable number of recent graduates who will choose to study for part-time graduate students in the postgraduate degree.

\section{On the identity of the student}

The reform of the enrollment system has made the status of non-full-time professional degree graduate students a diversified feature. In the past, the identity of students was unified as an in-service graduate student, and on-the-job learning was its most fundamental feature. Under the new policy, there are two types of candidates, social workers and fresh graduates. There are four types of part-time graduate students who have been in the incumbent, previous non-employed, fresh in-service, and non-working.

\section{The training of non-full-time professional degree master students under the new enrollment system}

\section{Require higher quality of culture}

The "Notice" clearly states: adhere to the same quality standards for full-time and part-time postgraduate education, and its academic degree certificate has the same legal status and the same effect, from the system level to the requirements for the quality of part-time professional degree graduate students. From the overall effect of education, the full-time professional degree master student is an important part of graduate education in China. The quality of training directly affects the overall quality and social reputation of graduate education in China. From the perspective of fairness, since the part-time and full-time postgraduate degree certificates have the same legal status and the same effect, the two players will compete on the same platform in the future, which directly requires the promotion of the quality of the postgraduate degree of part-time professional degree.In addition, the improvement of the quality of students and the demand for employment have prompted the training units to pay attention to the quality of the training of part-time graduate students.

\section{The source structure is complicated}

The complexity of the part-time graduate student source structure is mainly reflected in the four aspects of large age span, different professional background, different social experience and different places of study. 
Different age groups. Most of the exams that take part-time exams have certain work experience, so the age span will be larger. According to the new policy of the Department of Education, candidates who graduated from undergraduate courses can apply for the exams, except for those who are not required to apply for part-time professional degree programs such as MBA. This type of candidate usually has no work experience and is the youngest in the class.

The professional background is different. Among the full-time candidates, the proportion of continuing to pursue majors will be more, and among the part-time candidates, the proportion of undergraduate non-professionals will be higher. Some candidates who are engaged in this major hope to improve their professionalism by continuing their studies. Those who are not undergraduate in this major may wish to take this major to learn new professional skills, so as to lay the foundation for finding their ideal work in the future.

Different social experiences. Part-time candidates usually have different social experiences. These candidates may come from different industries, different units, and different roles in the work. Some people may be newcomers in the workplace, but some may have obtained senior professional titles; some are grassroots employees, and some are already supervisors in the organization.

There are cases of learning in different places. Because part-time candidates do not usually provide accommodation, there are many places where candidates work in different cities.

\section{The enrollment link lacks specificity}

After the introduction of the new policy, full-time postgraduate and part-time postgraduate enrollment will be merged, and the enrollment examinations for part-time postgraduate students will be included in the national postgraduate examinations. The graduate students of the same professional form will be re-tested on the same score line. The principle of "unified line" for full-time graduate students and part-time postgraduates is to adhere to the standard of uniform standards and the same quality, which is conducive to improving the quality of part-time graduate students and enhancing the society's confidence in the quality of part-time postgraduate training; On the other hand, the "unified line" rule has greatly increased the difficulty of part-time examinations. The fresh graduates have sufficient time to prepare for the exam, and the incumbent candidates are unable to fully prepare for the exam because of work and family involvement. The candidates of the recent graduates have more advantages in the examination than the in-service candidates. This is inconsistent with the original intention and training objectives of the part-time graduate students, which greatly dampens the enthusiasm of the in-service candidates to take part-time graduate students.

In addition, in the retesting session, although many training units re-examine the full-time candidates and part-time candidates, they all implement the same set of procedures and standards, and more are the professional basis for assessing candidates, and do not fully consider part-time. The training goal of graduate students is to train high-level professionals to serve social practice. The general re-testing process is not conducive to the selection of high-quality students with rich practical experience and innovative ability.

\section{The culture mode is not targeted}

The recruitment process is not targeted. Many current training units will be part-time graduate student education leech on to over full-time graduate education, following a full-time project of cultivating graduate student education, curriculum and degree awarding system, 
makes the curriculum content of part-time and full-time graduate students convergence convergence, evaluation forms, teaching mode, a part-time graduate student curriculum content simplification, elective course selection range of small, specialized fundamental course start order lag, difficult to meet the demand of part-time graduate student diversity goals, hinder the part-time graduate student education quality improvement.

Part-time graduate students have a greater need for practical teaching. At present, the form of part-time postgraduate education is often the same as that of full-time postgraduate students. There is no special consideration for the higher demand for part-time graduate students for practical teaching such as case teaching and special lectures. In addition, part-time graduate students are affected by time and geography, and sometimes it is difficult to guarantee full attendance to classes. Therefore, students have great demands for online teaching, but many training units lack supporting resources and experience in online teaching.

\section{Loose management}

Because part-time graduate students must pay attention to their studies and work, they are limited by time and geography, and they have less energy for learning. They often relax their demands on their thoughts and attitudes, which greatly increases the difficulty for the training units to manage their education. Most of the training units implement the same management methods for full-time postgraduate and part-time postgraduate students, and there is no targeted management method. On the other hand, the training unit does not strictly implement the management method, and there is a problem that the system implements different standards. For example, in the classroom attendance, because part-time graduate students mostly concentrate on lectures on weekends or evenings, the training units are negligent in the implementation of attendance work; in the performance assessment and thesis defense, the training units often relax the requirements for part-time graduate students, and have passed, teaching and the quality of the training is greatly reduced.

\section{Social cognition needs to be improved}

Although the General Office of the Ministry of Education has published the No. 2 Document of the Institute of Education and Research (2016) to co-ordinate the management of full-time graduate students and part-time graduate students, it is difficult for the community to recognize the recognition of part-time graduate students in a short period of time. It is understood that most employers and even human resources administrative units have misunderstandings about the concept of part-time, and the part-time postgraduate and non-dispatch qualifications are equated, and the recruitment policy has not been adjusted. The qualification requirements are still visible everywhere in the recruitment brief. The word of a full-time graduate student. This makes the first batch of "new part-time graduate students" who are currently studying at school feel anxious and distressed. The limitation of education export will have a huge negative impact on part-time postgraduate education. The enthusiasm of students in learning is low, the willingness of candidates to apply for examination, and the low willingness of tutors are not conducive to the virtuous circle of development of part-time postgraduate education.

\section{Students lack a sense of belonging to the school}

After the graduation of part-time postgraduate students, it is a high-quality alumni resource of the school. However, due to the lack of time for part-time postgraduate students, the lack of participation in school activities, the loose management of school education, and the lack of 
humanistic care in schools, part-time graduate students are often lacking in schools. A sense of belonging and cultural identity.

\section{The proposal for the development of part-time postgraduate education}

\section{Student-oriented, refined management}

The training unit needs to raise awareness and invest more energy and resources in part-time postgraduate education. Based on the characteristics of multi-disciplinary postgraduate students with complex structure and diversified target requirements, students-centered, with each training link as the carrier, based on the semester grades or the school study time, implement refined student status and training process management. . For example, subdividing different directions in the same profession to meet the different needs of different students for the course content, different needs for learning time and form.

\section{Innovative adaptation to the enrollment mechanism and training mode of part-time postgraduate education}

In the enrollment process, optimize the preliminary subjects and content of part-time professional degrees. Using the same paper to select full-time and part-time professional degree talents to ensure the quality of students, the original intention is good, but the difference between the incumbent and the full-time students is neglected, and the characteristics of the selection of professional degree talents are not reflected. Therefore, in addition to retaining the necessary basic knowledge, the preliminary examination of the part-time professional degree in the future should try to adjust and optimize the assessment practice ability, problem-solving ability, professional quality, professional ethics, etc., and more in the book industry. Actual questions and cutting-edge hotspots are included in the exam content. In addition, the examination subjects can also use the original GCT examination method to combine and standardize the contents of the examinations, and only do basic ability assessment. The preliminary examination subjects and contents that have been optimized and adjusted are more suitable for the reform of the unified examination papers for professional degrees.

In terms of curriculum, due to the large proportion of cross-professional candidates for part-time postgraduate students, the training unit should pre-position the professional foundation courses to lay a solid professional foundation for part-time graduate students; increase the number and diversity of elective courses, and increase the crossover. The number of subject courses gives students more choices: setting up curriculum generation and exit mechanisms to better serve the pragmatic characteristics of part-time projects; improving teaching methods, strengthening independent learning and interaction, and improving the quality of case teaching Establish a network information platform, and some elective courses are carried out in the form of online teaching, breaking the time and geographical restrictions.

\section{Encourage teachers to engage in teaching and student guidance}

Reform the evaluation system of college teachers, change the current status of teachers' light teaching and scientific research, improve the awareness of college teachers on the identity of "student training first responsible person"; encourage tutors to go out of school, actively participate in school-enterprise cooperation, and accumulate practical work experience, Good guidance for part-time graduate students. 


\section{Multi-party efforts to improve social awareness}

China has implemented a unified recruitment of full-time and part-time graduate students in the system, which will help improve the society's recognition of the quality of its students, but wants to improve the overall part-time graduate education results of the public and employers. It is far from enough to recognize and solve the education export problem of part-time graduate students. As an important window for the society, in order to enhance social influence, improve the quality of part-time postgraduate education, and ensure the social and economic benefits of part-time graduate students, we should continue to take a series of measures from other aspects, such as strengthening School conditions and teacher equipment, and increase part-time education. Only when the whole society truly recognizes and accepts part-time graduate students, can part-time postgraduate education be truly developed, and truly achieve qualitative progress, in order to provide more comprehensive talents for the country in a multi-directional direction, in order to embark on a situation that suits China's national conditions. The road to the development of part-time postgraduate education.

\section{Emphasis on the opinions of part-time students and enhance their recognition of the school}

Pay attention to the opinions and needs of part-time postgraduates, and enable students to participate in curriculum evaluation, teacher evaluation and education management to enhance students' sense of participation; to understand student needs through symposiums or questionnaires, to answer students' confusion and enhance students' sense of belonging Invite non-full-time graduates to return to school, give play to the alumni's mental infection and cultural communication, and cultivate alumni awareness and cultural identity of part-time students.

\section{Establish and improve the external quality assurance system}

On the macro level, the competent government departments should establish and improve the quality evaluation system for part-time postgraduate education as soon as possible, and withdraw from the full-time postgraduate education to construct an evaluation system separately. The establishment of the education quality assessment system is of great significance for enhancing the supervision of the training units, putting the opinions on construction reform into practice, and improving the reputation and social influence of part-time postgraduate education.

\section{Summary}

Since the pilot began in the 1980s, China's part-time postgraduate education has gone through more than 30 years, and has exported a large number of high-level talents for the country's modernization. However, in recent years, part-time postgraduate education generally has problems such as lack of pertinence in training management mode, complicated learning objectives, and insufficient social cognition. Compared with full-time graduate students, there is a big gap in all aspects. At this stage, in order to achieve the improvement of the quality of part-time postgraduate education, it must be co-operated by the training unit, the state, and the society. In response to these problems, the author proposes corresponding solutions from the three aspects of training units, countries and society, and strives to gradually shorten the gap between part-time postgraduate education and full-time postgraduate education, strengthen the 
overall management and standardized management of postgraduate education, and promote The construction of a learning society promotes the overall scientific development of the degree and postgraduate education in China.

\section{Acknowledgment}

This research was financially supported by: 2017BJJ075; 2018-ZZJH-616; 182400410151.

\section{References}

[1] Yang Yanhai, Zhang Xu, Yang Ye, Analysis of Existing Problems and Countermeasures of Part-time Postgraduate Education, J. Journal of Shenyang Jianzhu University (Social Science Edition), 2017(10).

[2] Wang Dingming, Yang Lijun, Unified Standard and Normative Management: A New Stage of Part-time Postgraduate Education, J. China Postgraduate, 2017(1): 4-8. 